\title{
openheart Angiotensin receptor blockers for prevention of cardiovascular disease: where does the evidence stand?
}

\author{
Flávio Danni Fuchs, ${ }^{1}$ James J DiNicolantonio ${ }^{2}$
}

To cite: Fuchs FD,

DiNicolantonio JJ. Angiotensin receptor blockers for prevention of cardiovascular disease: where does the evidence stand?. Open Heart 2015;2:e000236. doi:10.1136/openhrt-2014000236

Received 30 December 2014 Revised 9 March 2015 Accepted 17 March 2015

\section{CrossMark}

\begin{abstract}
${ }^{1}$ Serviço de Cardiologia, Hospital de Clínicas de Porto Alegre, UFRGS, Porto Alegre, Brazil

${ }^{2}$ Department of Preventive Cardiology, Saint Luke's Mid America Heart Institute, Kansas City, Missouri, USA
\end{abstract}

Correspondence to Professor Flávio Danni Fuchs; ffuchs@hcpa.ufrgs.br

\section{ABSTRACT}

Angiotensin receptor blockers (ARBs) are the most commonly used among blood pressure-lowering drugs worldwide, despite the absence of sound evidence of effectiveness in large and unbiased clinical trials. Metaanalyses published in recent years and reviewed here have not given support to this preference, suggesting that ARBs may be ineffective in the prevention of all cause mortality and major cardiovascular events (particularly myocardial infarction). There is evidence that ARB can be harmful for the kidney, particularly in patients with diabetes and in the elderly. It may be time to call for a moratorium on the preference for ARB in the management of hypertension and in patients with high cardiovascular risk.

Angiotensin receptor blockers (ARBs) are the most commonly used blood pressurelowering drugs in the world. Nonetheless, the results of large trials and meta-analyses published in recent years and reviewed here have not given support to this preference, suggesting that they may be ineffective in the prevention of all cause mortality and major cardiovascular (CV) events ( particularly myocardial infarction). Moreover, there is evidence that ARBs can increase the incidence of acute kidney damage, particularly in patients with diabetes and in the elderly. It may be time to call for a moratorium on the preference for ARB in the management of hypertension and in patients with high cardiovascular risk.

In a descriptive review, we identified that ARBs were ineffective in preventing CV outcomes in seven large placebo-controlled trials in patients with high $\mathrm{CV}$ risk. ${ }^{1}$ In five of these studies, the treatment with an ARB was not superior to placebo in the prevention of major CV events, ${ }^{2-6}$ and in two there was higher CV mortality in patients treated with an ARB instead of placebo. ${ }^{7} 8$ Moreover, treatment with ARBs was associated with worse renal outcomes in some trials, such as increased incidence of microalbuminuria, renal impairment and decreased glomerular filtration rate. ${ }^{6} 7^{9-11}$ The presumptive efficacy of ARB in the prevention of atrial fibrillation was not confirmed by four large studies specifically designed to investigate this effect. ${ }^{6}$ 12-14

Four meta-analyses of these and other trials converged in the identification of lack of effectiveness of ARBs in the prevention of major cardiovascular outcomes. The first explored the efficacy of ARBs in the prevention of myocardial infarction and other $\mathrm{CV}$ outcomes. ${ }^{15}$ Patients had various criteria for enrolment in the trials included in this meta-analysis, such as hypertension, heart failure, diabetes, stroke, atrial fibrillation and others. In total, 37 randomised clinical trials (RCTs), with 147020 participants, were evaluated. When compared with placebo or active treatment, ARBs were ineffective in the prevention of myocardial infarction (relative risk (RR) $0.99,95 \%$ CI 0.92 to 1.07 ), death, cardiovascular death or angina pectoris. Compared with controls, ARBs were associated with a reduction in the risk of stroke, heart failure and new onset diabetes.

The second meta-analysis investigated the efficacy of renin-angiotensin-aldosterone system (RAAS) inhibitors over CV morbiditymortality trials. ${ }^{16}$ The trials should have at least two-thirds of patients with hypertension. The meta-analysis included 158998 patients. RAAS inhibition either with ACE inhibitors (ACEi) or ARB was associated with a 5\% reduction in all-cause mortality (RR 0.95, 95\% CI 0.91 to 1.00 ) and a $7 \%$ reduction in CV mortality (RR $0.93,95 \%$ CI 0.88 to 0.99 ). When the trials were divided by the class of RAAS inhibitor, the effect was identified to be entirely due to ACEi (RR 0.90, 95\% CI 0.84 to 0.97$)$. Treatment with an ARB had no effect in the prevention of all-cause mortality (RR $0.99,95 \%$ CI 0.94 to 1.04 ).

Another meta-analysis explored the efficacy of ACEi and ARB in the prevention of 
cardiovascular disease (CVD) in patients with diabetes and hypertension. ${ }^{17}$ Compared to placebo or other active treatment, in 23 studies with 32827 patients with diabetes, ACEi significantly reduced the risk of all-cause mortality by $13 \%$ (RR $0.87 ; 95 \%$ CI 0.78 to 0.98 ), the incidence of $\mathrm{CV}$ deaths by $17 \%(0.83 ; 0.70$ to 0.99$)$, major CV events by $14 \%(0.86 ; 0.77$ to 0.95$)$, including myocardial infarction by $21 \%(0.79 ; 0.65$ to 0.95$)$ and heart failure by $19 \%(0.81 ; 0.71$ to 0.93$)$. In contrast with the effectiveness of ACEi, ARBs were ineffective in reducing the risk for all-cause mortality (RR 0.94; $95 \%$ CI, 0.82 to 1.08 ) in 13 studies controlled by placebo or other active treatment, with a total of 23867 patients with diabetes. With the exception of a reduction in the risk of heart failure $(0.70 ; 0.59$ to 0.82$)$, ARBs were ineffective in the prevention of CV death (1.21; 0.81 to 1.80$)$ and major CV events $(0.94 ; 0.85$ to 1.01$)$.

A fourth meta-analysis addressed the efficacy and safety of ARB in elderly patients, in comparison with active and placebo comparators. ${ }^{18}$ A total of 113386 participants were included. The incidence of all-cause mortality and myocardial infarction were higher and marginally significant in participants treated with ARB (RR $1.03,95 \%$ CI 1.00 to 1.06 and $1.04,95 \%$ CI 0.96 to 1.12 , respectively). Stroke and heart failure were less frequent in patients treated with an ARB. Hypotension and hyperkalemia were more common with ARB. A more striking result, however, was the $48 \%$ increase in the risk of acute kidney injury (95\% CI from $24 \%$ to $97 \%$ ). This risk was similar to the risk described in individual studies. ${ }^{1}$

The only study where an ARB was superior to the comparator was the LIFE trial. ${ }^{19}$ This study compared losartan with atenolol, a $\beta$-blocker known to be ineffective in the prevention of cardiovascular events in elderly patients. ${ }^{20}$ Additionally, despite the fact that losartan significantly reduced stroke compared to atenolol, there were fewer patients with atrial fibrillation, tobacco use and isolated systolic hypertension at baseline in the losartan arm, giving an unfair advantage-specifically to the stroke end point-that achieved significance. ${ }^{21}$ The possibility that the LIFE trial is an outlier was demonstrated in the meta-analysis of patients with diabetes. ${ }^{17}$ In the analysis with an active control group, the large heterogeneity $\left(\mathrm{I}^{2}=49 \%\right)$ was mainly derived from the LIFE study. After excluding the LIFE study, heterogeneity and a trend for efficacy of ARB disappeared $\left(\mathrm{I}^{2}=0 \%\right.$; RR $0.96 ; 95 \%$ CI 0.77 to 1.20 ).

It is hard to explain how ARBs have reached such a high level of preference in the treatment of hypertension worldwide, in the face of this overwhelming volume of evidence demonstrating that they are probably ineffective in the prevention of all-cause mortality and many manifestations of $\mathrm{CV}$ disease. The excessive valorisation of the first studies performed with these drugs, which investigated surrogate outcomes and were underpowered to evaluate the effects over hard outcomes, may have originated the misconception about their efficacy. The basic research was oriented to the investigation of mechanisms of action and effects of these drugs, and the number of manuscripts describing favourable effects of ARBs on experimental models is uncountable. The massive commercial promotion of ARBs also had a key role in the establishment of this preference. Many scientists and opinion leaders worked towards helping pharmaceutical companies to proclaim the superiority of ARBs over traditional blood pressure-lowering drugs, despite the absence of head-to-head comparisons with diuretics in large RCTs. In addition, three RCTs published in influential journals, which had showed very favourable effects of ARB, were recently retracted because of scientific fraud. ${ }^{22-24}$

The guidelines for the management of hypertension, led mostly by the same opinion leaders, share the recommendation that ARBs should be the first options to treat hypertension, particularly in patients with diabetes and renal disease. ${ }^{25-27}$ These almost homogeneous recommendations surely had a major role in the generation of the common belief about the superiority of ARBs. And finally, doctors contributed to this preference, since in the daily clinical practice they perceived that these drugs were well tolerated (ie, 'ACEi without the cough') and could not obviously perceive their inefficacy to prevent $\mathrm{CV}$ outcomes. In the face of frequent unsatisfactory blood pressure control with an ARB alone, diuretics used to be added to the ARB to get better blood pressure response.

The preference for ARBs is not supported by evidence in the literature and may be denying patients the benefits of being treated with proven blood pressure-lowering agents. It may be time to call for a moratorium on the preference for ARBs in the prevention of CVD in patients with hypertension or diabetes.

Contributors FDF and JJD selected the manuscripts for the review and prepared the review.

Funding Hospital de Clínicas de Porto Alegre Instituto Avaliação de Tecnologias em Saúde.

Competing interests None declared.

Provenance and peer review Not commissioned; externally peer reviewed.

Data sharing statement No additional data are available.

Open Access This is an Open Access article distributed in accordance with the Creative Commons Attribution Non Commercial (CC BY-NC 4.0) license, which permits others to distribute, remix, adapt, build upon this work noncommercially, and license their derivative works on different terms, provided the original work is properly cited and the use is non-commercial. See: http:// creativecommons.org/licenses/by-nc/4.0/

\section{REFERENCES}

1. Fuchs FD. The role of angiotensin receptor blockers in the prevention of cardiovascular and renal disease: time for reassessment? Evid Based Med 2013;18:44-7.

2. Lithell H, Hansson L, Skoog I, et al. The Study on Cognition and Prognosis in the Elderly (SCOPE): principal results of a randomized double-blind intervention trial. J Hypertens 2003;21:875-86.

3. Yusuf S, Teo K, Anderson C, et al., Telmisartan Randomised AssessmeNt Study in ACE iNtolerant subjects with cardiovascular Disease (TRANSCEND) Investigators. Effects of the angiotensin-receptor blocker telmisartan on cardiovascular events in 
high-risk patients intolerant to angiotensin-converting enzyme inhibitors: a randomized controlled trial. Lancet 2008;372:1174-83.

4. Yusuf S, Diener HC, Sacco RL, et al., PRoFESS Study Group. Telmisartan to prevent recurrent stroke and cardiovascular events. N Engl J Med 2008;359:1225-37.

5. McMurray JJ, Holman RR, Haffner SM, et al., NAVIGATOR Study Group. Effect of valsartan on the incidence of diabetes and cardiovascular events. N Engl J Med 2010;362:1477-90.

6. Yusuf S, Healey JS, Pogue J, et al., ACTIVE I Investigators. Irbesartan in patients with atrial fibrillation. N Engl J Med 2011;364:928-38.

7. Haller $\mathrm{H}$, Ito $\mathrm{S}$, Izzo JL Jr, et al., ROADMAP Trial Investigators. Olmesartan for the delay or prevention of microalbuminuria in type 2 diabetes. N Engl J Med 2011;364:907-17.

8. Imai E, Chan JC, Ito S, et al., ORIENT study investigators. Effects of olmesartan on renal and cardiovascular outcomes in type 2 diabetes with overt nephropathy: a multicentre, randomised, placebo-controlled study. Diabetologia 2011;54:2978-86.

9. Mauer M, Zinman B, Gardiner R, et al. Renal and retinal effects of enalapril and losartan in type 1 diabetes. $N$ Engl $J$ Med 2009;361:40-51.

10. Yusuf S, Teo KK, Pogue J, et al., ONTARGET Investigators. Telmisartan, ramipril, or both in patients at high risk for vascular events. N Engl J Med 2008;358:1547-59.

11. Mann JF, Schmieder RE, Dyal L, et al., TRANSCEND Investigators. Effect of telmisartan on renal outcomes: a randomized trial. Ann Intern Med 2009;151:1-10.

12. Disertori M, Latini R, Barlera S, et al., GISSI-AF Investigators. Valsartan for prevention of recurrent atrial fibrillation. $N$ Engl J Med 2009;360:1606-17.

13. Goette A, Schön N, Kirchhof $P$, et al. Angiotensin II-antagonist in paroxysmal atrial fibrillation (ANTIPAF)-trial. Circ Arrhythm Electrophysiol 2012;5:43-51

14. Yamashita T, Inoue H, Okumura K, et al. Randomized trial of angiotensin II-receptor blocker vs. dihydropiridine calcium channel blocker in the treatment of paroxysmal atrial fibrillation with hypertension (J-RHYTHM II Study). Europace 2011;13:473-9.

15. Bangalore S, Kumar S, Wetterslev J, et al. Angiotensin receptor blockers and risk of myocardial infarction: meta-analyses and trial sequential analyses of 147020 patients from randomised trials. BMJ 2011;342:d2234.

16. van Vark LC, Bertrand M, Akkerhuis KM, et al. Angiotensinconverting enzyme inhibitors reduce mortality in hypertension: a meta-analysis of randomized clinical trials of renin-angiotensin- aldosterone system inhibitors involving 158998 patients. Eur Heart $J$ 2012;33:2088-97.

17. Cheng J, Zhang W, Zhang X, et al. Effect of angiotensin-converting enzyme inhibitors and angiotensin II receptor blockers on all-cause mortality, cardiovascular deaths, and cardiovascular events in patients with diabetes mellitus: a meta-analysis. JAMA Intern Med 2014:174:773-85.

18. Elgendy IY, Huo T, Chik V, et al. Efficacy and safety of angiotensin receptor blockers in older patients: a meta-analysis of randomized trials. Am J Hypertens 2014. Published Online First: 11 Nov 2014. doi:10.1093/ajh/hpu209

19. Dahlöf B, Devereux RB, Kjeldsen SE, et al., LIFE study group. Cardiovascular morbidity and mortality in the Losartan Intervention for Endpoint reduction in hypertension study (LIFE): a randomised trial against atenolol. Lancet 2002;359:995-1003.

20. Fuchs FD. Losartan for cardiovascular disease in patients with and without diabetes in the LIFE study. Lancet 2002;359:2203.

21. Strauss M and Hall A. Angiotensin receptor blockers should be regarded as first-line drugs for stroke prevention in both primary and secondary prevention settings: no. Stroke 2009:40:3161-2.

22. [No authors listed]. Retraction-combination treatment of angiotensin-II receptor blocker and angiotensin-converting-enzyme inhibitor in non-diabetic renal disease (COOPERATE): a randomised controlled trial. Lancet 2009;374:1226.

23. Lancet Editors. Retraction - valsartan in a Japanese population with hypertension and other cardiovascular disease (JIKEI HEART STUDY): a randomised, open-label, blinded endpoint morbidity-mortality study. Lancet 2013;382:843.

24. [No authors listed]. Retraction of: effects of valsartan on morbidity and mortality in uncontrolled hypertensive patients with high cardiovascular risks: KYOTO HEART Study. Eur Heart $J$ 2013;34:1023

25. Mancia G, Fagard R, Narkiewicz K, et al. 2013 ESH/ESC Guidelines for the management of arterial hypertension. $J$ Hypertens 2013;31:1281-357.

26. James PA, Oparil S, Carter BL, et al. 2014 Evidence-based guideline for the management of high blood pressure in adults: report from the panel members appointed to the Eighth Joint National Committee (JNC 8). JAMA 2014;311:507-20.

27. Krause T, Lovibond K, Caulfield M, et al., Guideline Development Group. Management of hypertension: summary of NICE guidance. BMJ 2011;343:d4891. 